\title{
A Scanning and Transmission Electron Microscopic Study of Contractile Trabecules in the Rat Spleen
}

\author{
By \\ Kazuo KIMURA, Takami FUSANO and Yoko TANAKA \\ Department of Anatomy (Director Prof. M. Miyoshi), Fukuoka University School of Medicine, Fukuoka 814-0180, \\ Japan \\ - Received for Publication, August 10, 2001 -
}

Key Words: Contractile trabecules, Red pulp, Rat spleen, EM

\begin{abstract}
Summary: The fine structures of contractile trabecules in the splenic red pulp of the rat were examined by electron microscopy to elucidate their participation in the active contraction of the spleen.

Numerous fine thready trabecules were developed in the red pulp. They were enveloped with a cytoplasmic layer of reticular cells and consisted of elongated smooth muscle cells, fascicles of collagenous fibrils and elastic fibers. Their fibrous components in the capsular ends extended in a triangular form of fanribs into the fibrous tunica of the capsule. Smooth muscle cell-like interstitial cells (SIC) were situated in the interfibrous spaces. Flattened SICs were affixed with cytoplasmic processes to the elastic lamina. The trabeculocapsular junctions were represented on the elastic lamina by grouped or isolated circular patches with concentrically arranged triangular processes and were also observed on the capsular serosa by plaques with scarce microvilli of serosal cells. Smooth muscle cells of the fine trabecules were equipped on the cell surface with anchoring structures to extracellular fibrous elements as previously described by Gabella (1981). Close associations were also seen between the smooth muscle cells and elastic fibers which were terminated to the fascicles of collagenous fibers. Cell-to-cell connections were expressed by fibrous connections between spiny processes and a small number of puntate intermediate junctions and nexuses. Unmyelinated nerve fibers with adrenergic terminals were seen in the intercellular spaces.

We propose that for the rat spleen, the fine trabecules in the red pulp are muscular contractiles which are reponsible for the active contraction due to sympathetic stimuli and the administration of $\alpha_{1}$-adrenoceptor agonists, while the elastic lamina in the capsule plays a role in the comprehensive contraction of the subcapsular vascular bed.
\end{abstract}

The recent concept of splenic hemodynamism is that circular constrictions of large venous sinuses lead to blood pooling in the sinuses and reticular spaces in the splenic cords and the relaxation of the sinual constrictors and functional obliterations of the lienal arterioles are thus able to mobilize the pooled blood into the systemic circulation (Amenta and Amenta, 1990; Groom and Schmidt, 1990). On the other hand, electrical stimuli of sympathetic nerves (Davies and Withrington, 1973) and the administration of $\alpha_{1}$-adrenocepter agonists (adrenalin, noradrenalin, phenylepherine etc.) proved that the active squeezing out of blood from the spleen is attained by splenic contraction due to smooth muscle cells in the capsule and trabecules (Davies and Withrington, 1973). In laboratory rodents, however, extremely few smooth muscle cells are found in the capsule (Tischendorf, 1968; Kai, Nishizono and Kimura, 2000) and elastic fibers are more highly developed than the musculature (Gross,
1951; Tischendorf, 1968). A strong contraction of the spleen in rodents has also been reported in pharmacological experiments in the rat (Aboud, Schhaffi and Docherty, 1993; Burt et al., 1995; Stam, V. Graaf and Saxena, 1998), mouse (Eltze, 1996), and rabbit (Oriowo, 1998) which is considered to be due to a large amount of smooth muscle cells.

In this sense, we focused our attention on the thin trabecules (Tischendorf, 1968) in the rat splenic pulp, although these trabecules have been described by Herrath (1958) as muscular in blood storing type spleens (pig, horse, and carnivores) and as nonmuscular in functional type spleens (man, rabbit and laboratory rodents). The aim of the present study is to elucidate whether or not the fine trabecules are substantial contractiles containing smooth muscle cells with adrenergic innervations. The fine structural findings were discussed regarding the summation of the contraction force generated by muscle cells of the muscular trabecules. In addition, 
the physiological meaning of the capsular elastic lamina and elastic fibers in the trabecules was also discussed.

\section{Materials and Methods}

Thirty-five Wister rats of both sexes weighing about $250 \mathrm{~g}$ were used. The animals were anethestized by the intraperitoneal injection of $25 \mathrm{mg}$ pentobarbital- $\mathrm{Na} / \mathrm{kg}$ weight. Each animal was perfused by the descending aorta with $40 \mathrm{ml}$ of Ringer's solution to rinse out the blood in the vessels, and then, with $250 \mathrm{ml}$ fixatives. The fixatives used here consisted of $2.5 \%$ glutaraldehyde in $0.1 \mathrm{M}$ phosphate buffer adjusted to $\mathrm{pH} 7.4$ and $10 \%$ paraformaldehyde in $0.1 \mathrm{M}$ cacodylate buffer adjusted to $\mathrm{pH}$ 7.4. All perfused specimens were kept in the same fixative for one week at room temperature.
For TEM observation: The glutaraldehyde-fixed specimens were cut into small pieces, post-fixed with $1 \%$ osmium tetroxide in $0.1 \mathrm{M}$ phosphate

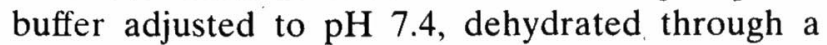
series of graded ethanol and propylene oxide, and were embedded in Epon epoxy resin. Thin sections of plastic-embedded specimens were made, and stained with uranium nitrate and lead citrate. Some sections were immersed in tannic acid solution to stain the elastic fibers before metal staining (Watanabe and Nishizono, 1994). Observations were performed using a Hitachi H-7000 TEM.

For SEM observation: (1) Specimens of the serosal tunica were prepared from glutaraldehydefixed materials. Tissue blocks with surfaces for observation (about $5 \times 5 \times 3 \mathrm{~mm}$ ) were made. (2) Collagenous fibers were exposed by the immersion of tissue blocks $(5 \times 5 \times 3 \mathrm{~mm})$ in $10 \%$ sodium hydroxide for 5 days at $20^{\circ} \mathrm{C}$ (Ohtani, 1987).

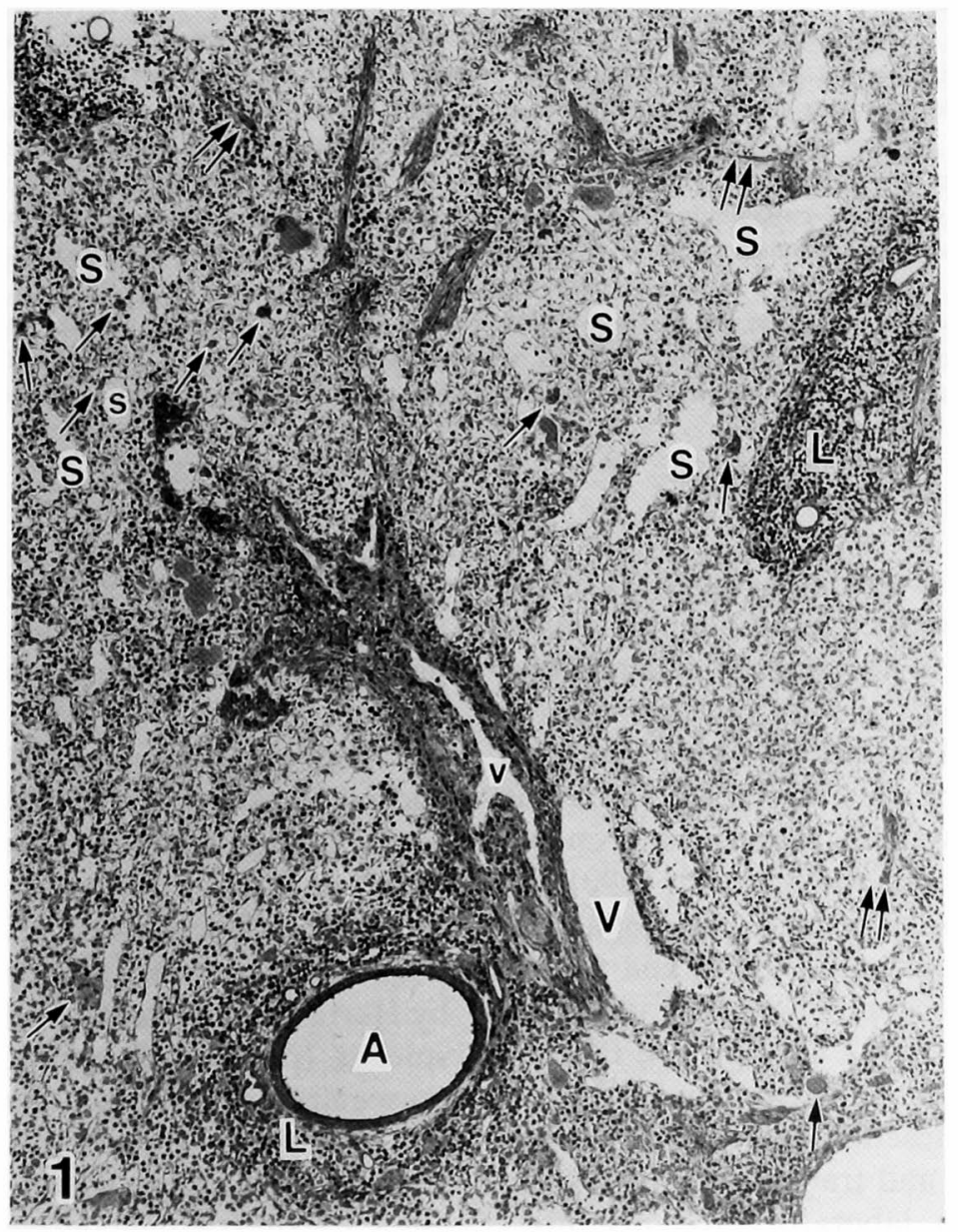

Fig. 1. A LM image of a trabecule with blood vessels and its surrounding red pulp in a tangential section to the capsule. In the pulpa reticulum, fine dot-(arrows) and twig-like figures (double arrows) are seen to be disseminated. A: An artery with lymphatic sheath $(\mathrm{L}), \mathrm{S}$ : venous sinuses, V: veins in the trabecule with branchings. $\times 125$ 
(3) Elastic fibers were exposed by the immersion of tissue blocks (about $5 \times 5 \times 3 \mathrm{~mm}$ ) of paraformaldehyde-fixed materials in $90 \%$ formic acid for 4 days at $45^{\circ} \mathrm{C}$ (Ushiki, 1992), and rinsed with McIlvane buffer adjusted to $\mathrm{pH} 3$. All tissue blocks mentioned above were immersed in $0.1 \%$ aqueous solution of tannic acid (for the elastic fiber, $0.1 \%$ tannic acid in McIlvane buffer mentioned above) for $0.5 \sim 1 \mathrm{hr}$, washed throughly with distilled water, and then post-fixed with $1 \%$ osmium teroxide in phosphate buffer mentioned above for $2 \mathrm{hrs}$. The post-fixed specimens were rinsed with distilled water, dehydrated through a series of graded ethanol, placed in $t$-butylalcohol, and then desiccated by the frozen-dry method. After the fixation of dried specimens on metal blocks, their surfaces were coated with gold-palladium alloy in an evaporator. Observations were made with a Hitachi S-450 and a S-3100H SEM.
Thick sections of plastic-embedded specimens were made, stained with $1 \%$ toluidine blue in $0.1 \%$ phosphate buffer mentioned above, and then were observed light microscopically (LM).

\section{Observations}

LM and TEM observation: In cross or tangential sections to the capsule, the thick trabecules containing blood vessels were few in number ( $\mathrm{Ti}$ schendorf, 1968) and non-vascular thin trabecules with dot-like or twig figures in cross or longitudinal sections were found in a LM graph to be disseminated in the reticular spaces of the red pulp (Figs. 1. $2,3)$. The thin trabecules with branchings in an EM graph were circular threads (Figs. 2, 3) measuring about 30 to $20 \mu \mathrm{m}$ in thickness. Each of them was sheathed with a thin cytoplasmic layer of reticular
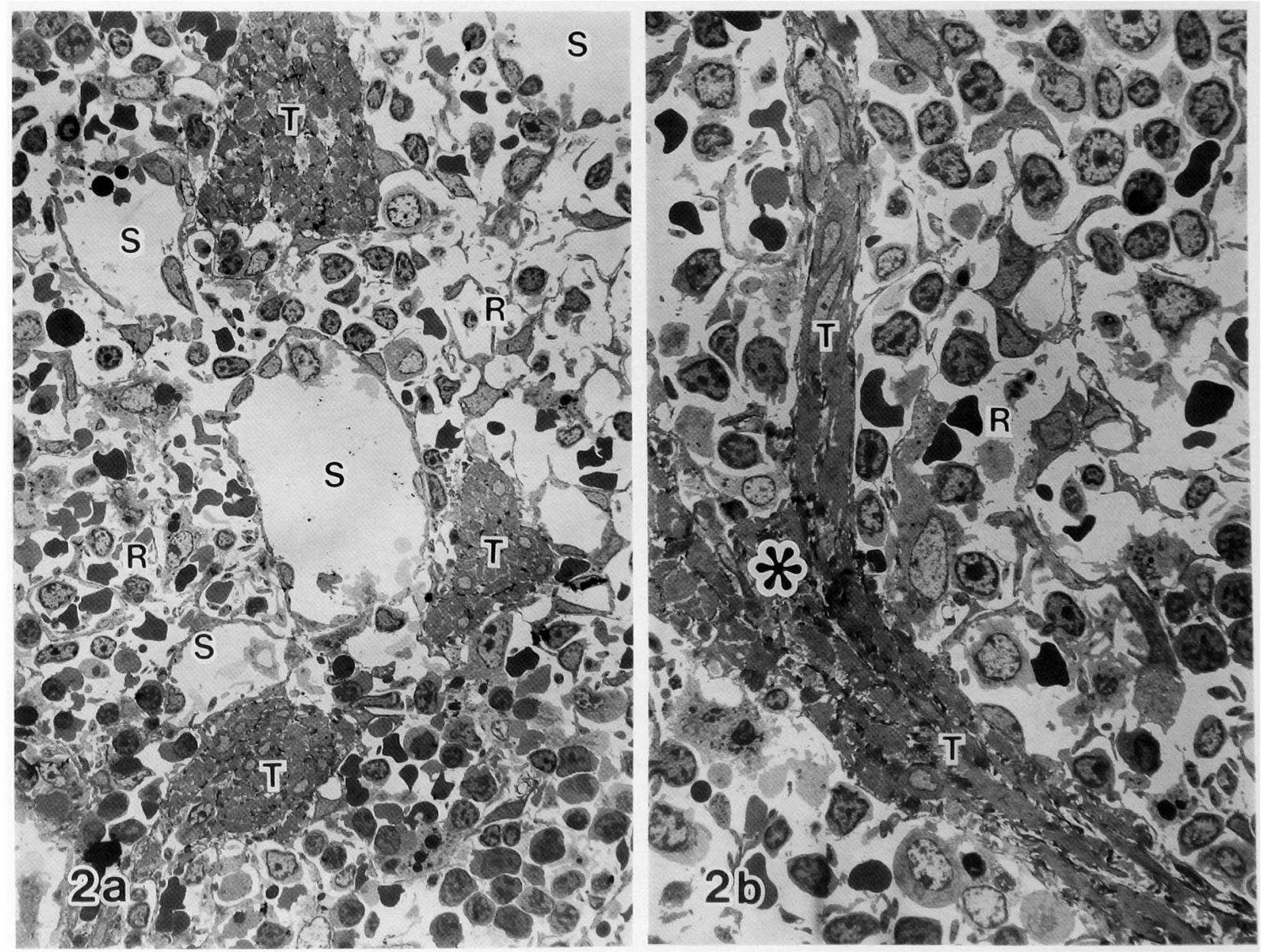

Fig. 2. TEM images of fine trabecules (T) in cross (a) and longitudinal sections (b) with a branch (asterisk) in the reticulum (R) between the venous sinuses $(S)$ which contain numerous smooth muscle cells. a: $\times 630 \mathrm{~b}: \times 950$ 

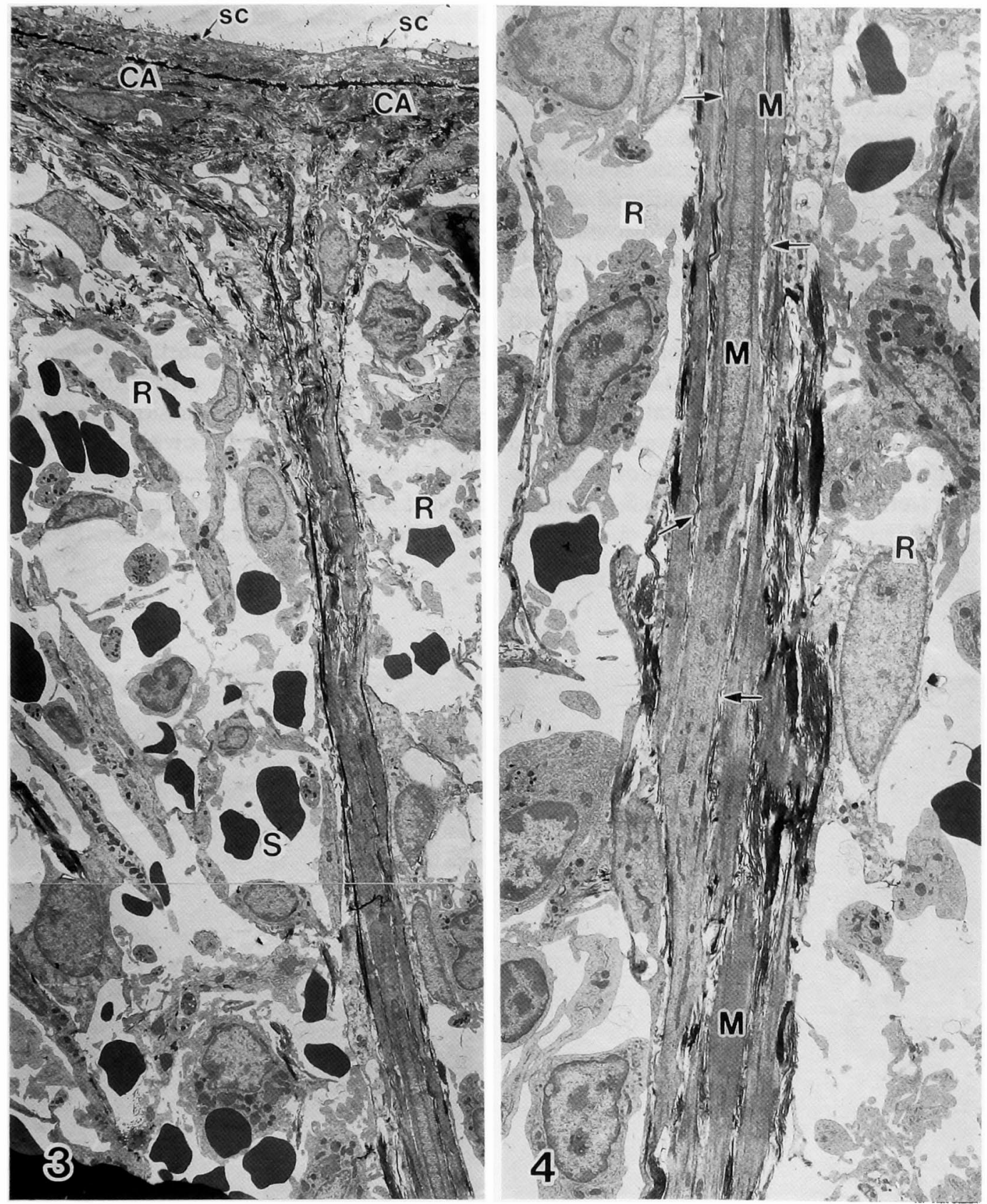

Fig. 3. A longitudinally sectioned view of a fine trabecule and its capsular junction. Fiberous muscle cells and intercellular fiberous elements are extended along the long axis of the trabecule at its main portion and are transferred in their triangular divergence into the fibrous tunica at a capsular end. CA: capsule, R: reticulum, $\mathrm{S}$ : venous sinuses, SC: serosal cells $\times 1,800$

Fig. 4. A longitudinally sectioned view of a fine trabecule. Muscle cells (M) with tapered ends and some spiny processes are braced with intercellular fibrous elements (arrows). R: reticulum $\times 3,000$

Fig. 5. A cross section of a fine trabecule. It is sheathed with reticular cells (RC) and their thin cytoplasm (arrows). Fascicles of collagenous fibers (CF) and densely stained elastic fibers (E) intervene muscle cells (M) and cytoplasmic processes of the indented muscle cells (IM). Direct junctions (thick arrows) of mucle cells are punctate and scarce. Unmyelinated nerves (encircled) are seen in the intercellular spaces. $\mathrm{R}$ : reticulum $\times 5,000$

Inserted is a close-up of unmyelinated nerve with a cluster of small cored vesisles (arrows). $\times 14,000$ 


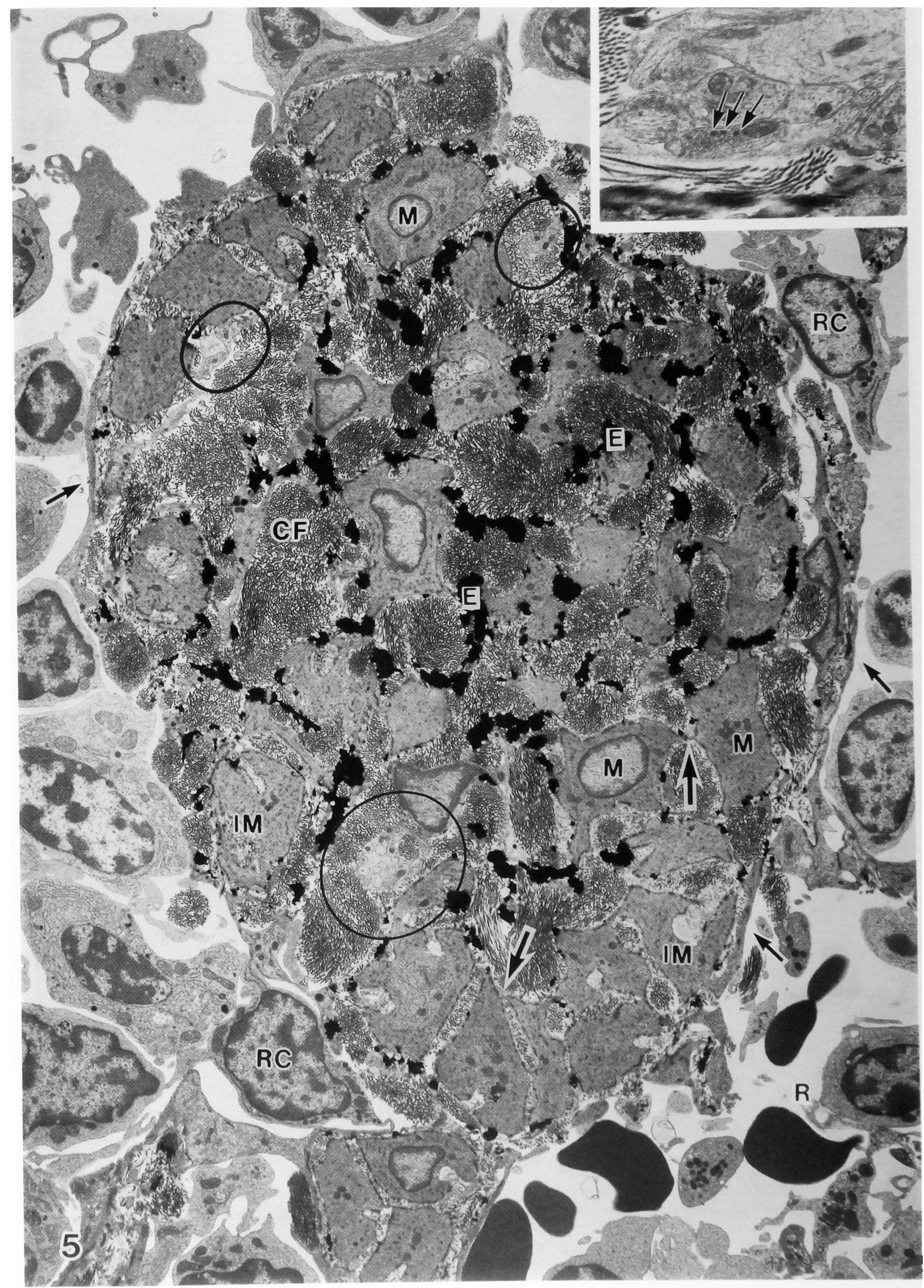



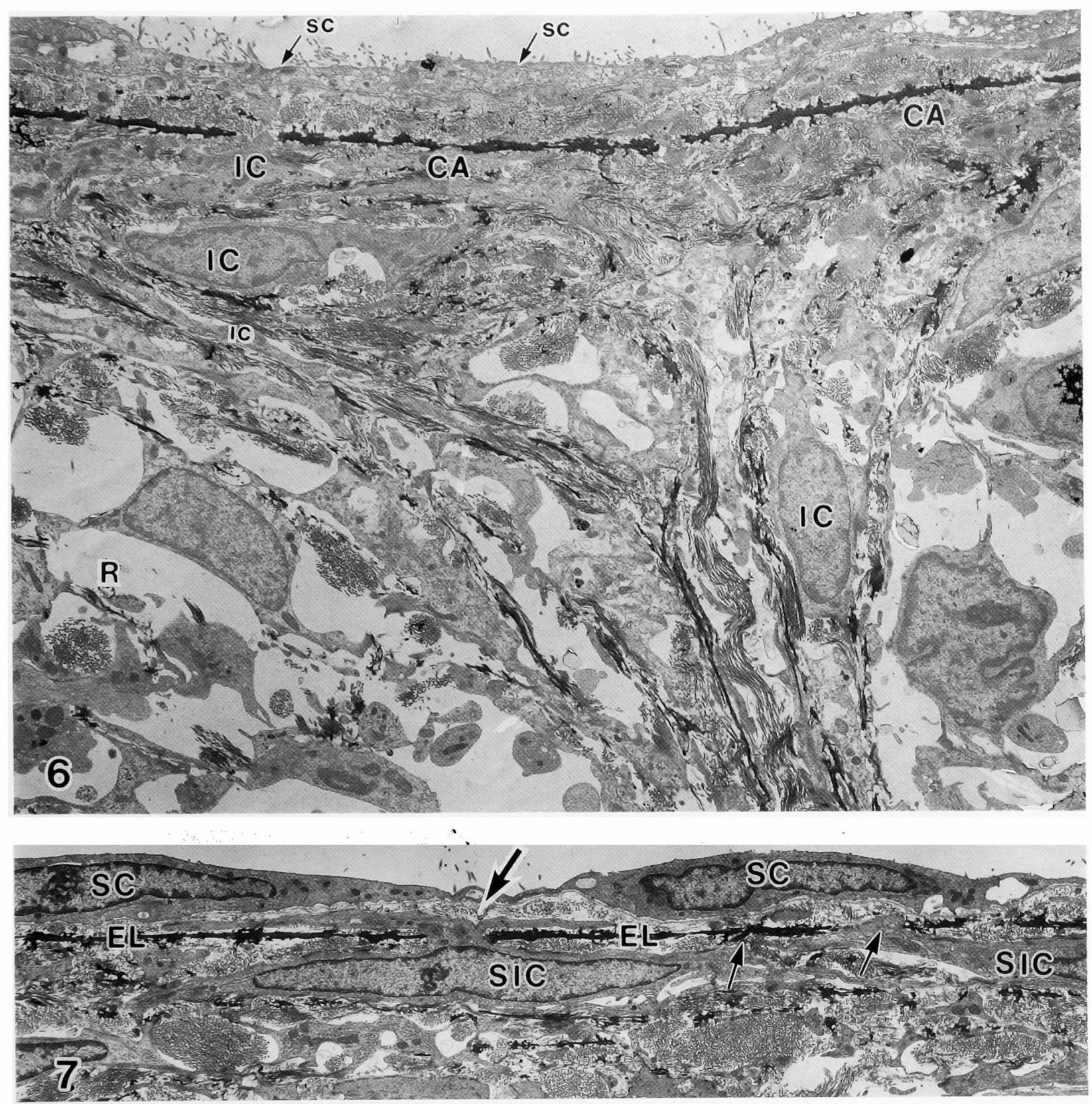

Fig. 6. A perpendicular section of trabeculocapsular junction. Fibrous elements of the fine trabecule are spreaded out into the fibrous tunica of the capsule (CA) covered with thin cytoplasm of serosal cells (SC). Variouly formed interstitial cells (IC) are situated among the fibrous elements. $\mathrm{R}$ : reticulum $\times 4,300$

Fig. 7. Smooth muscle-like interstitial cells (SIC) are affixed with their small processes (arrows) which are associated with fascicles of collagenous fibers to the elastic lamina (EL). A long process penetrates through the lamina (large arrow). SC: serosal cells. $\times 4,800$

Fig. 8. An SEM image of a free surface of the serosa. In the free surface with microvilli, bared plaques (asterisks) of various sizes are disseminated, suggesting the existence of trabeculocapsular junctions. $\times 750$

Fig. 9. A subserosal surface of exposed elastic lamina. Circular patches (P) with concentrically arranged processes. The areas among the patches are rippled with fine rugae. $\times 370$ 

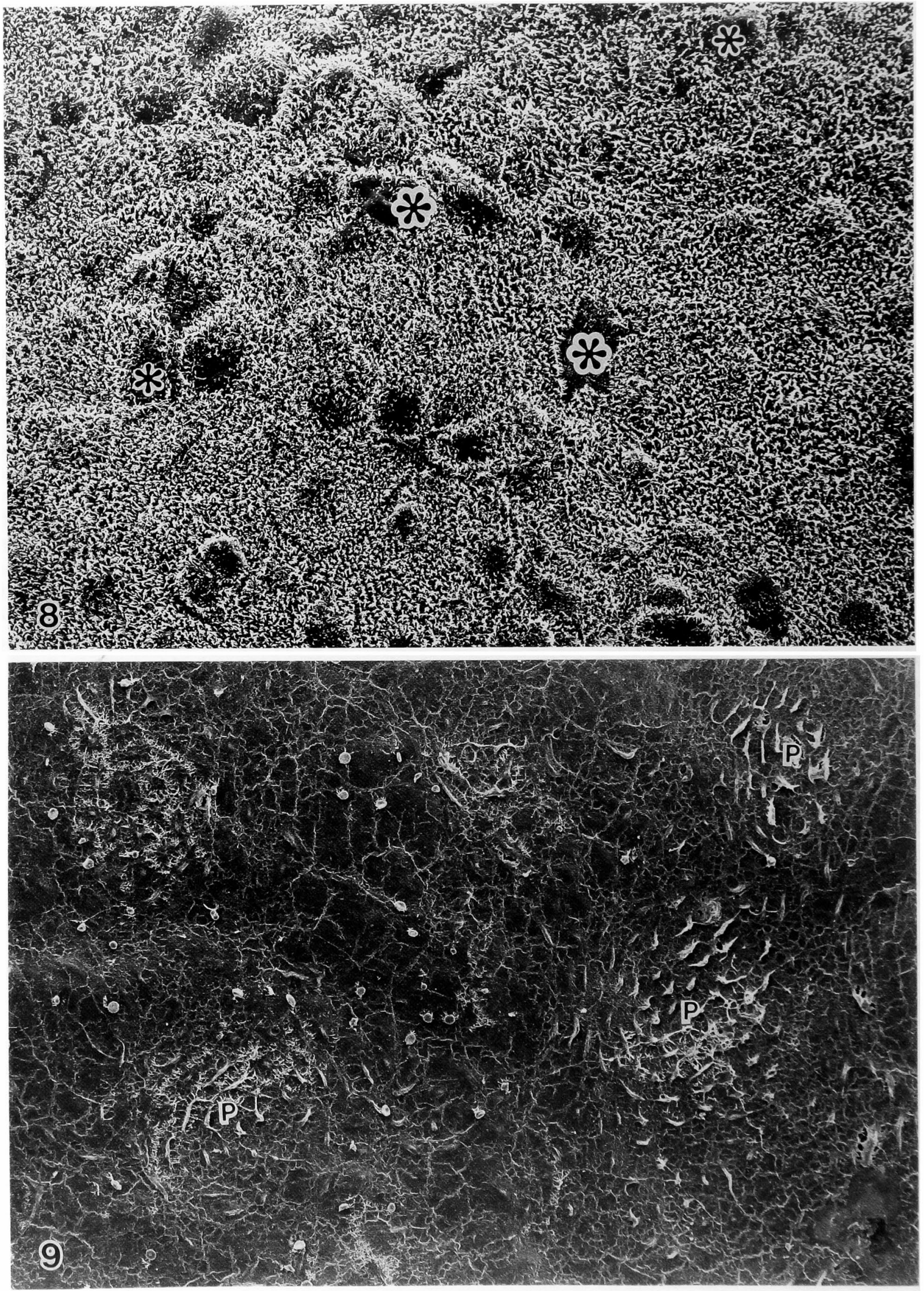
cells and contained many smooth muscle cells (Figs. $2,4,5$ ), extending along the long axis of the trabecules. Their typical cytoplasmic structures were similar to those of vertebrate smooth muscle cells as previously described in a text book (Fawcett, 1986) or review (Gabella, 1981) (Figs. 4, 5, 16). The cells with punctate intercellular connections of the nexus and intermediate junctions were usually interposed with evenly enmeshed fascicles of collagenous fibers and elastic fibers (Fig. 5). Nerve terminals with cored vesicles were also found in the intercellular spaces (Fig. 5). Capsular ends of the thin trabecules extended their fibrous components in a triangular form of fan-ribs into the fibrous capsule beneath the elastic lamina. Variously formed smooth muscle cells and smooth muscle cell-like interstitial cells (SIC) were situated between the fibrous ribs (Figs. 3, 6). Flattened SIC were affixed with variously sized processes to the basal surface of a porous elastic lamina and some cytoplasmic processes extended through pores together with fascicles of collagenous fibers (Figs. 6, 7, 13). The supralaminar area was occupied with a thin layer of collagenous fibers and of branches from the elastic lamina (Fig. 7). In addition, the trabeculocapsular junctions were covered with a thin cytoplasmic layer of serosal cells with scarse microvilli (Figs. 6, 7).

SEM observation: The serosal surface exhibited a sporadical dissemination of variously sized plaques. They included pavements of penta- or hexagonal cell surfaces with nuclear swellings and were distinct from the surrounding serosal area with well developed microvilli (Fig. 9). The exposed elastic lamina was finely rippled and exhibited circular patches which were either grouped or isolated (Figs. 10, 12). The paches measured about $120 \mu \mathrm{m}$ in diameter and were equipped with a concentrical arrangement of triangular processes measuring about $2 \mu \mathrm{m}$ in height, some of which were associated with a pore measuring about $1 \mu \mathrm{m}$ in thickness on their tops or variously sized lacerations at their bases. The pores and lacerations correlated with the penetrations of cytoplasmic processes of underlying SIC and of fascicles of collagenous fibers respectively. Some processes of the same one patch extended many branches with fine twigs (Fig. 11) which were observed in sections as processes of the elastic lamina (Fig. 7).

After removing the elastic fibers and lamina, the external surface of the fibrous tunica was covered with a net of fascicles of collagenous fibers which extended to the cytoplasmic channels of the serosal cells covering intertrabecular capsule (Kai et al., 2000) (Fig. 12). The fibrous net showed frequent occurrences of rough-surfaced plaques, which were covered with villous processes (Fig. 12) instead of fascicles. The processes consisting of fine fibrils were arranged in a similar manner to that of the circular patches on the exposed elastic lamina (Fig. 13).

EM observations at high magnification: The trabecular muscle cells came in close contact with intercellular fibrous elements. On the lateral surface of the muscle cells, collagenous fibrils were connected with patchy basal laminae on the sites of cytoplasmic dense plaques (Fig. 15). Elastic fibers were also associated with the cell membrane which was intercalated with extracellular fibrilar components on the fiber surface (Fig. 16). Fibrous connections of neighboring cells were formed between the spiny processes, to which the cytoplasmic filaments also converged (Figs. $14 \mathrm{a}$ and $\mathrm{b}$ ). It was usual that the fibrous connections were interchanged with elastic fibers which were interposed in extension of the collagenous fibrils or at their junctional areas on smooth muscle cells (Figs. $14 \mathrm{a}$ and b).

\section{Discussion}

Our study provides morphological evidence that the thin trabecules described by Cohrs and Schulz (1958) and Tischendorf (1969) in the rat spleen are specifically developed contractile structures consisting of smooth muscle cells and elastic fibers among the fascicles of collagenous fibers. Herrath's (1958) description that the fine trabecules in the splenic red pulp of the rodents spleen are nonmuscular might be due to the low resolution of the light microscope. Furthermore, the trabecules extend in the intersinual reticular tissue to be connected with the fibrous tunica of the capsule. Their situation in the red pulp is suggested to be effective

Fig. 10. A close-up of an isolated patch. Processes in a flattened triangular form are concentrically arranged. Some of them show a round pore (arrows) or radiating processes at their lateral surface (circled). $\times 700$

Fig. 11. A close-up of triangular processes with radiating thread-like processes (arrows). These processes with ramifying fine processes were radiated from the lateral surface of the triangular processes, at the base of which large lacerations (asterisks) are seen. $\times 3,000$ 

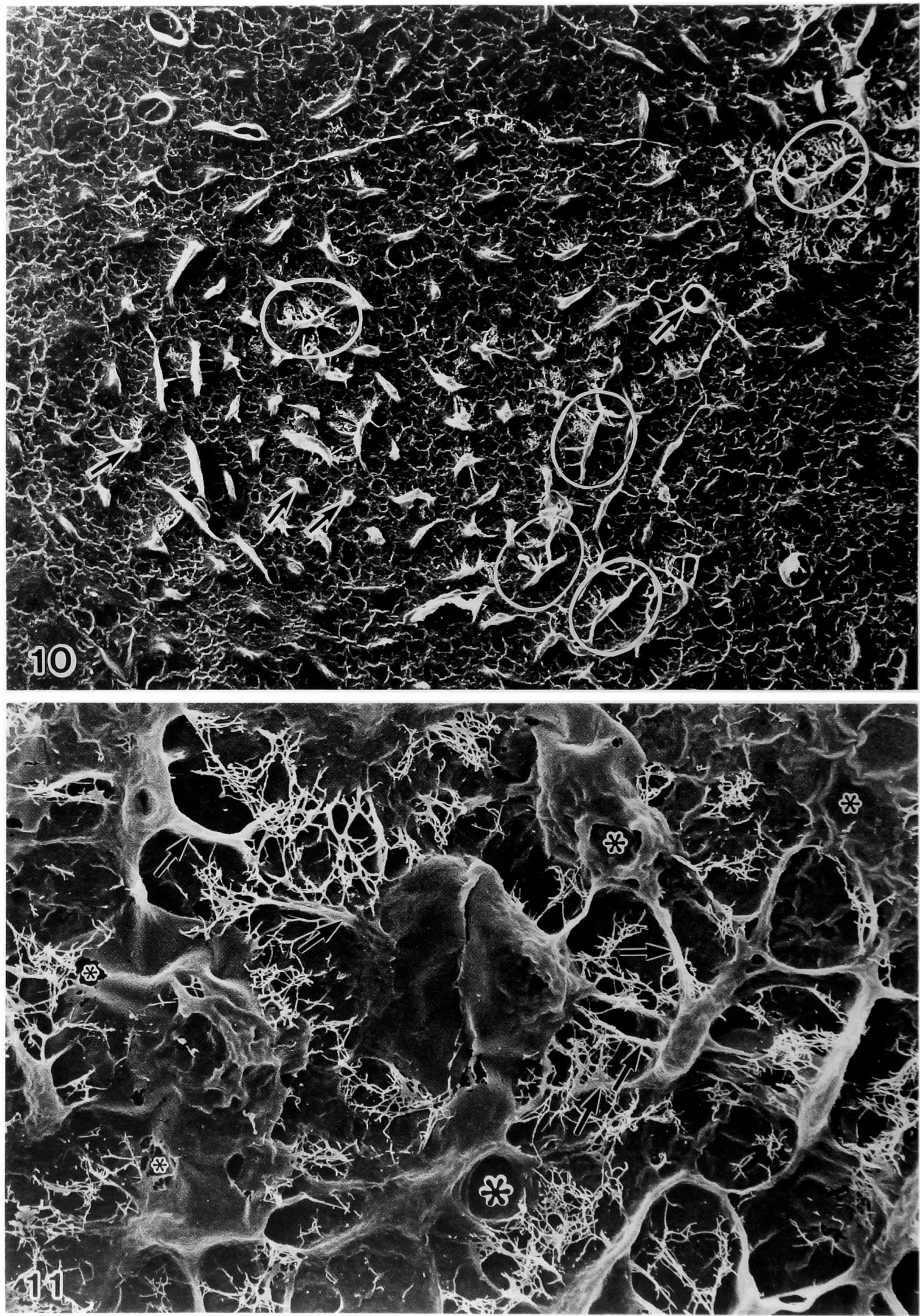
for the contraction of large sinuses arranged as covering fingers in fan-shaped arrays in the splenic pulp (Schmidt, MacDonald and Groom, 1985). The well developed elastic fibers in the fibrous tunica (Kai, Nishizono and Kimura, 2000) may play a role in the comprehensive contraction of the subcapsular network of small sinuses with their mutual anastomoses (Schmidt, MacDonald and Groom, 1985).

The circular patches with concentrically arranged triangular processes on the elastic lamina occur at the trabeculocapsular junctions. Each patch seems to be represented by an interstitial cell affixed to the inferior surface of the lamina. The patches are almost completely uniform in size and their diameters are also closely similar to the extension of interstitial cells. The triangular processes of the patches are possibly caused by a horizontal contraction of the interstitial cells and by a local picking up of underlying collagenous fibrils into the elastic lamina at affixed potions of the interstitial cells. Furthermore, the interstitial cells and numerous branches of elastic fibers in the trabeculocapsular junction may produce a forceful contraction of dense connective tissue to replace the tissue fluid at the junctional area.

We observed the close contact of the smooth muscle cells with microfibrils of the extracellular tissue to patchy basal laminae along the lateral cell surface in the same manner as that described by Gabella $(1976,1981)$ in the viceral and vascular smooth muscles. In addition, we also observed the fibrous connections between the spiny processes of neighboring cells described as microtendons by Holstein et al. (1996) in the lamina propria of the seminiferous tubules.

The cell-to-stromal junctions and cell-to-cell junctions with stroma observed in the thin trabecules are considered to be suitable connections of smooth muscle cells to maintain the chained arrangement of the cells. The contraction force generated by smooth muscle cells are thus considered to be conveyed to the intercellular fascicles of the collagenous fibers and are accumulated to evoke a forceful contraction of the trabecules. The elastic fibers associated with the smooth muscle cells may be elastic microtendons which can be stretched to allow for the rapid pooling of blood, as those in muscular nets of the esophagus, vagina, aorta etc. as reviewed by Bargmann (1977).

\section{References}

1) Aboud $R$, Shafii $M$ and Docherty JR. Investigation of the subtypes of $\alpha_{1}$-adrenoceptor mediating contractions of rat aorta, vas deferens and spleen. Br J Pharmacol 1993; 109:80-87.

2) Amenta PS I and Amenta PS II. The anatomy of the spleen. In: (ed. by) Bowdler AJ: The spleen, Chapman \& Hall Medical, London, 1990 (p 3-7).

3) Bargmann W. Muskelgewebe. In: Histologie und Mikroskopische Anatomie des Menschen. 7th ed. pp 146-172, Georg Thieme Verlag, Stuttgart, 1977.

4) Burt RP, Chapple CR and Marshall I. Evidence for a functional alpha 1A-(alpha 1C-) adrenoceptor mediating contraction of the rat epididymal vas deferens and alpha $1 \mathrm{~B}$-adrenoceptor mediating contraction of the rat spleen. Br J Pharmacol 1995; 115(3):467-475.

5) Eltze $M$. Functional evidence for an $\alpha_{1 B}$-adrenoceptor mediating contraction of the mouse spleen. Eur J Pharmacol 1996; 311:187-198.

6) Fawcett D. A text book of histology. Igakushoin/Saunders Intnl, Tokyo, 1986:660.

7) Gabella $G$. The force generated by a visceral smooth muscle. J Physiol 1976; 263:199-213.

8) Gabella G. Structure of smooth muscles. In: Smooth muscle: an assessment current knowledge (ed. by Bülbring $\mathrm{E}$, Brading AF, Jones AW and Tomita T) chapt. 1:1-46 Edward Arnold Ltd, London, 1981.

9) Groom AC and Schmidt EE. Microcirculatory blood flow through the spleen. In: The spleen (Bowdle ed.) chap. 4:45-102 Chapman \& Hall Med, London, 1990.

10) Gross M. Zur Kentnis der Variationsbreite und des Feinbaues der normalen Milz von Laboratoriumratten. MedDiss Wurzburg, 1951.

11) Herrath Ev. Bau und Function der normalen Milz. Walter de Gruyter \& Co., Berlin, 1958.

12) Holstein AF, Maekawa $M$, Nagano $T$ and Davidoff MS. Myofibroblasts in the lamina propria of human seminiferous tubules are dynamic structures of heterogeneous phenotype. Arch Histol Cytol 1996; 59(2):109-125.

13) Kai $\mathrm{T}$, Nisizono $\mathrm{H}$ and Kimura $\mathrm{K}$. Fiber arrangement of the rat splenic capsule with special reference to elastic fibers. Okajimas Folia Anat Jpn 2000; 77(5):167-180.

14) MacKenzie DW, Whipple AO and Wintersteiner MP. Studies on the microscopic anatomy and physiology of living transilluminated mammalian spleens. Amer $\mathbf{J}$ Anat $1941 ; 68: 397-456$.

15) Oriowo MA. Functional characterization of $\alpha_{1}$-adrenoceptor subtypes in the rabbit spleen. Naunyn-Schmiedeberg's Arch Pharmacol 1998; 358:301-307.

16) Ohtain $O$. Three-dimensional organization of the con-

Fig. 12. A circular patch on the layer of collagenous fibers after removing the elastic fibers and cell elements. A rough area with villi is distinct from the surrounding area covered with a net of thick fascicles of collagenous fibers (NCF). $\times 750$

Fig. 13. A sector of the patch surface on the layer of collagenous fibers. The triangular processes (TP) are concentrically arranged. $\times 900$

The processes are formed with fine collagenous fibrils as seen in a cornered picture. $\times 2,500$ 

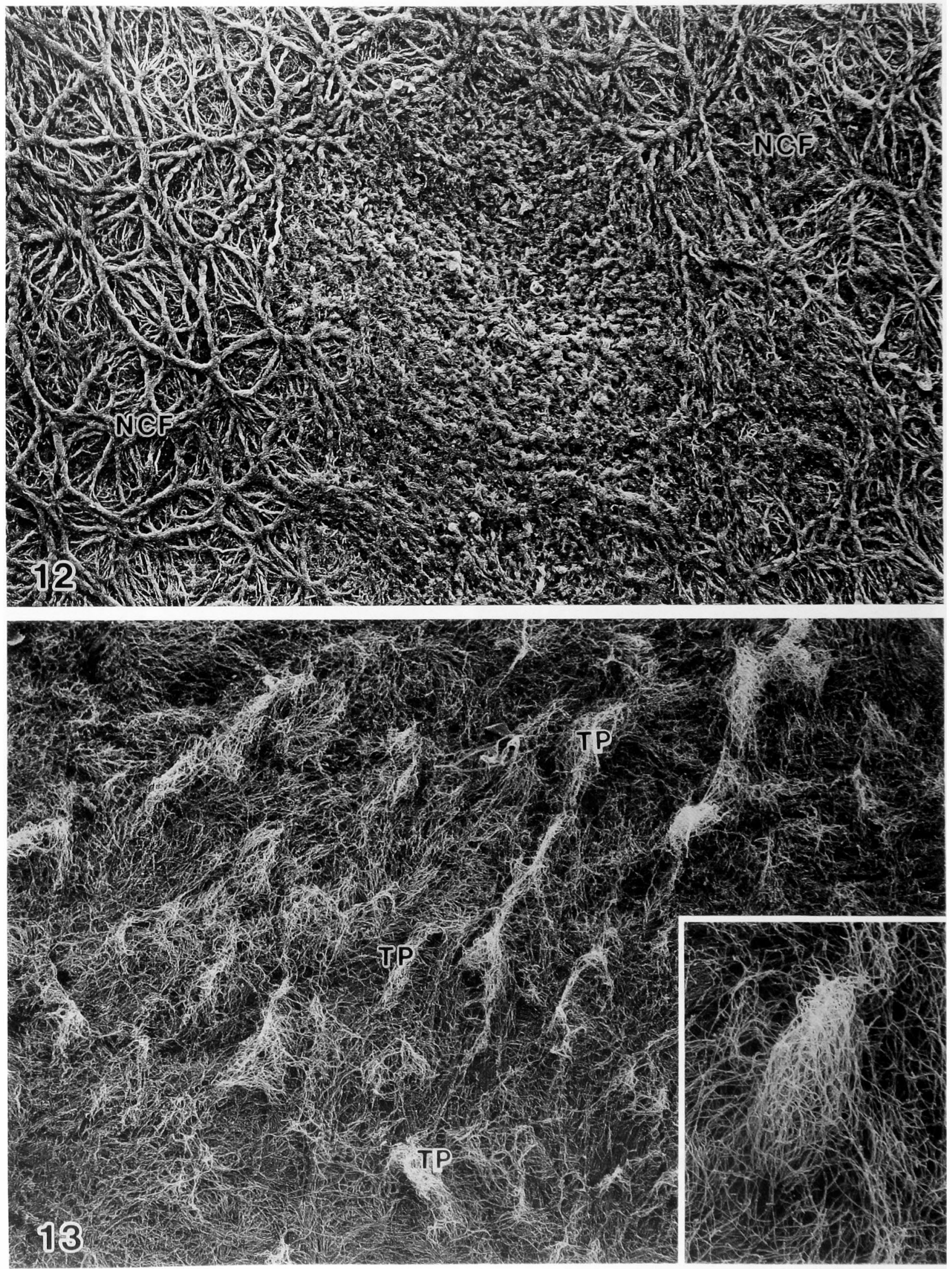
nective tissue fibers of the human pancreas: A scanning electron microscopic study of $\mathrm{NaOH}$ treated-tissues. Arch Histol Jpn 1987: 50(5):557-566.

17) Raviola E. Spleen. In: (ed. by) Fawcett: A textbook of histology, Capt. 16 pp 464-478, Igakushoin/Saunders Intnl, Tokyo, 1986.

18) Saito $H$. Innervation of the guinea pig spleen studied by electron microscopy. Am J Anat 1990; 189:213-235.

19) Schmidt EE, MacDonald IC and Groom AC. Microcirculation in rat spleen (sinusal), studied by means of corrosion casts, with particular reference to the intermediate pathways. J Morpohol 1985; 186:1-16.

20) Stam WB, Van der Graaf PH and Saxena PR. Functional characterization of the pharmacological profile of the pu- tative alpha 1B-adrenoceptor antagonist, (+)-cyclazosin. Eur J Pharmacol 1998; 361:79-83.

21) Tischendorf F. Mikroskopiche Anatomie der Milz. In: Handbuch der mikroskopischen Anatomie des Menschen. Die Milz. Springer-Verlag, Berlin, Heidelberg, N.Y., 1969 VI/6 (p 158-471).

22) Ushiki T. Preserving the original architecture of elastin components in the formic acid-digested aorta by an alternative procedure for scanning electron microscopy. J Electron Microsc 1992; 41:60-63.

23) Watanabe $\mathrm{N}$ and Nishizono $\mathrm{H}$. A scanning and transmission electron microscope study of fiber arrangement in the hepatic capsule. Okajima Folia Anat Jpn 1994; 71:279-296.
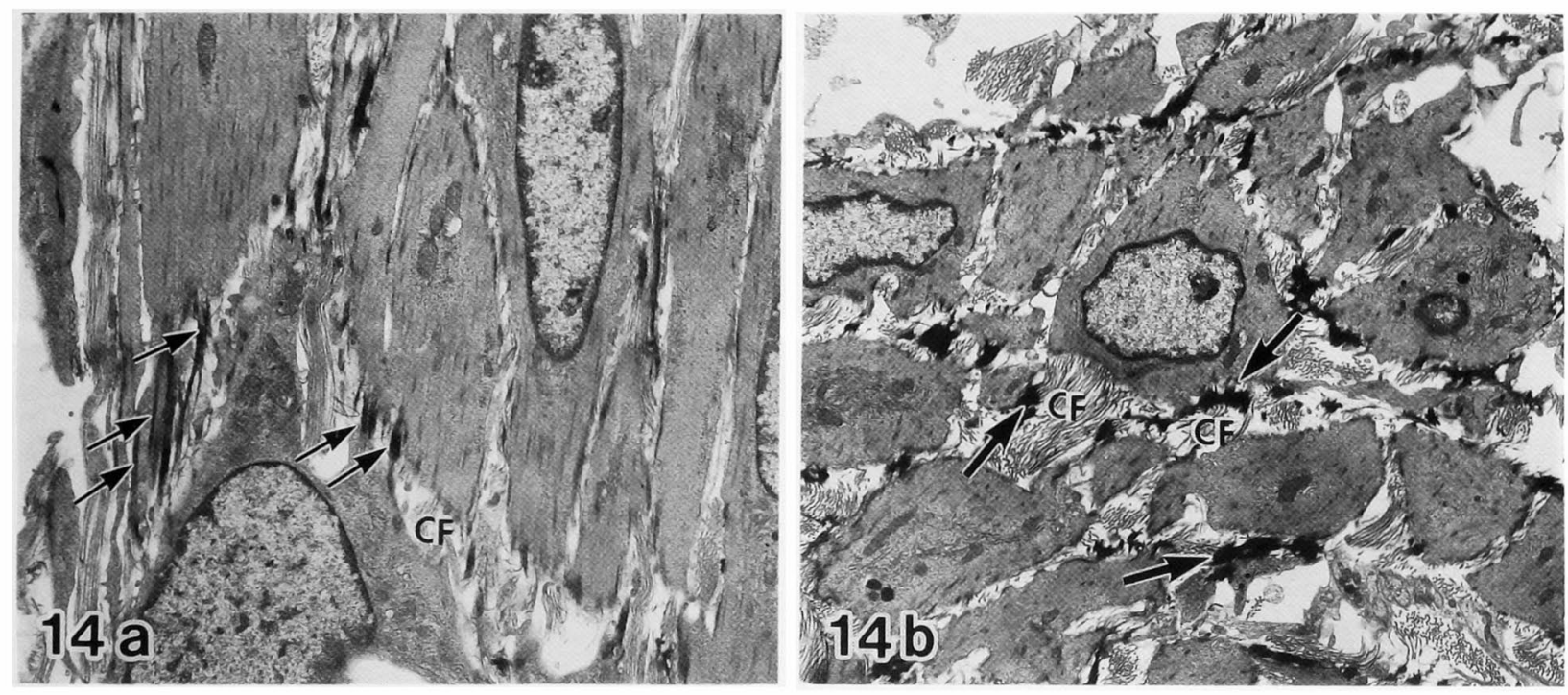

Fig. 14. The cell-to-cell connections by intercellular fibers in oblique (a) and cross sections (b). Fibrous connections with collagenous fibrils $(\mathrm{CF})$ are formed either between the cytoplasmic dense plaques or via densely stained elastic fibers (large arrows). Connections with only elastic fibers are also seen (small arrows). $a$ and $b: \times 4,700$ 

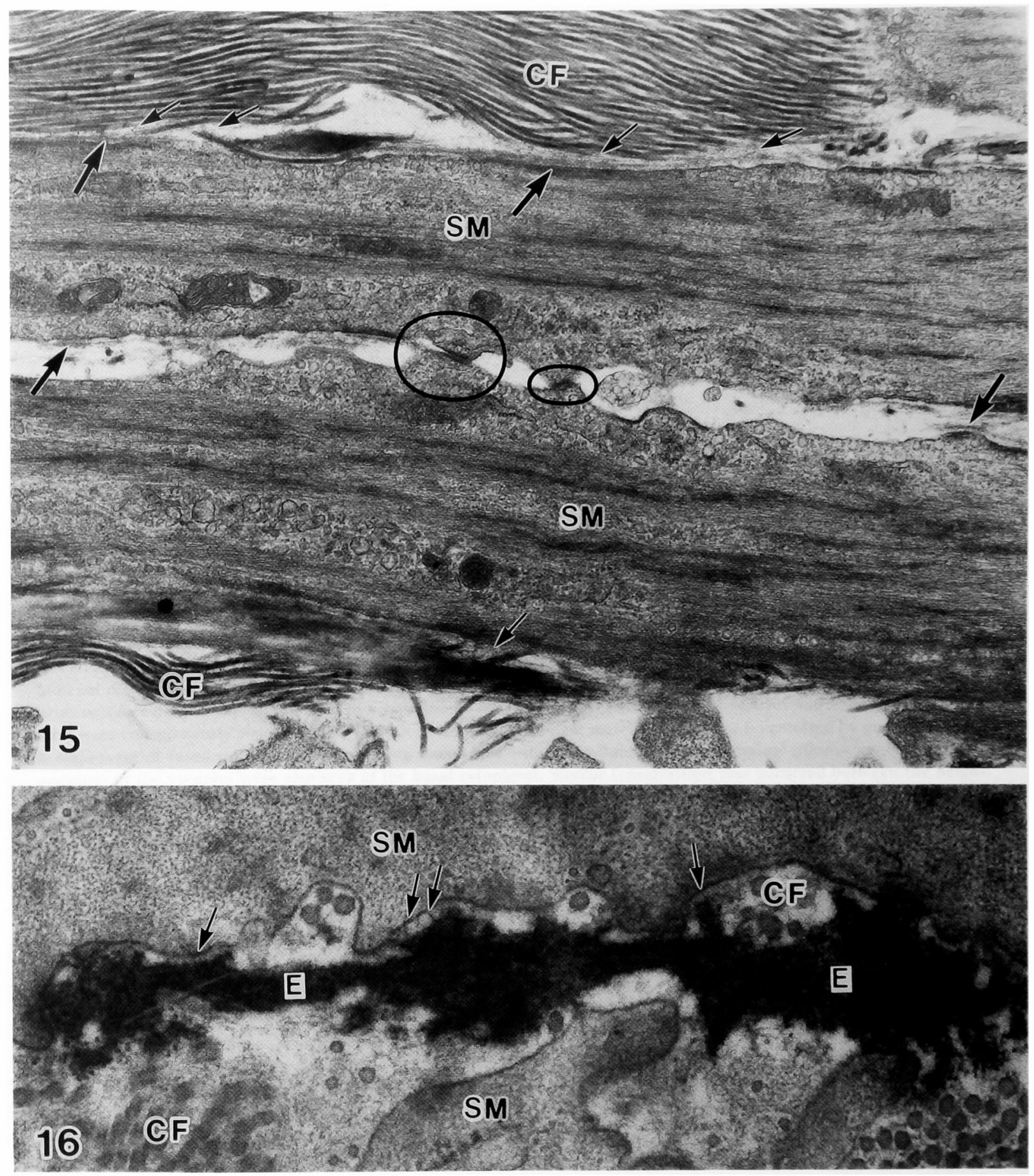

Fig. 15. A longitudinal section of cells (SM) and intercellular fibers. Intermediate junctions by an appositional connection of dense plaques (circled) are seen between the neighboring cells. Close associations of collagenous fibers (CF) are connected with extracellular fine fibrils (small arrows) from patchy basal lamina (large arrows) on the cell membrane. $\times 22,000$

Fig. 16. The connection between the elastic fibers (E) and muscle cells (SM). The arrows point to fine fibrils interposed between the dense plaques of the cyoplasmic membrane and elastic fiber. CF: collagenous fibers. $\times 30,000$ 